\title{
The Opioid Epidemic: What Pakistan can Learn from the US
}

In the United States of America, we are in the midst of a social pandemic, referred to as "The Opioid Epidemic." This is a problem not unique to America, but because it plagues America it illustrates the problem's multifactorial nature and also highlights that any country, regardless of affluence, can fall victim to this problem. The problem with opioid abuse is not a new one in America and can be traced at least as far back as the Civil War, where soldiers suffering from various war-related injuries were treated liberally with morphine resulting in widespread addiction, referred to at the time as "Soldier's Disease." However, despite growing awareness of the problem over time and despite several social and political initiatives to combat it, including establishment of both the Food and Drug Administration (FDA) and the Drug Enforcement Agency (DEA) that were charged with controlling opioid prescribing among other responsibilities and the late First Lady Nancy Reagan's famous "Just Say No" campaign in the 1980's, opioid abuse has persisted in America.

Opioid abuse represents both abuse of prescribed opioids such as morphine, oxycodone, hydrocodone, codeine, etc; but also abuse of illegal opioids such as cocaine and heroin. The current epidemicis unique in that it draws heavily from abuse of prescription opioids. The modern "Opioid Epidemic"can be traced back to approximately the year 2000. At that time, hospital patients' pain scored on a visual analog scale from 1 - 10 was designated the "fifth vital sign" after temperature, heart rate, blood pressure, and respiratory rate; warranting aggressive management. It is this singular event that a direct line can be drawn from when both patients began consuming more opioids and physicians began prescribing more. It was also at approximately this time, that the pharmaceutical industry came out with several long-acting opioids such as Oxycontin (Purdue Pharma - Stamford, Connecticut, USA). What resulted was a rising expectation by patients and society of aggressive and generous receipt of opioids and liberal prescribing by physicians. The result was an explosion of opioid prescriptions. Here are our current facts to consider. ${ }^{1}$
- American represents 5\% of the world's population but consumes $80 \%$ of the world's opioids.

- 260 plus opioid prescriptions are written annually, 3 times more than in 1999.

- $\quad 1.9$ million Americans are addicted to prescription opioids.

- 4 out of every 5 heroin users started their addiction with prescription opioids.

- 78 people die daily from an opioid-related overdose.

Fortunately, this has resulted in a pro-active response from both the American medical community and the political establishment. The American Attorney General, Dr. Vivek Murthy, recently took the unprecedented step to write a personal letter to all prescribing physicians in America engaging them to understand the problem, encouraging them to curb inconsiderate opioid prescribing, and recommended directing those patients with signs of addiction to receive early active treatment. Many states have also taken aggressive steps such as mandating opioid prescribing restrictions and requiring medical students and physicians to receive mandatory opioid prescriber training. Similarly, in our institution, we have studied our patients' opioid consumption and physician prescribing habits. Within the Orthopaedic Surgery department, we noted that on average patients were consuming 8 opioid pills on average after upper extremity surgery, yet physicians were prescribing 25 opioid pills on average, resulting in an inadvertent 3 fold over-prescribing pattern. $^{2}$ The results of this study surprised us all and has led us to establish prescription guidelines and prescribe opioids post-operatively more discriminately.

Pakistan is not immune to this problem. In some ways, it is more susceptible to it due to limitations in resources, greater poverty and illiteracy, and the active and ever increasing opioid production in Afghanistan making its way to Pakistan. A survey report published by the UN Office on Drugs and Crime in 2013 found that more that 6.7 million Pakistanis are estimated to have used opioid (including both heroin and opioids) in 2012 alone. ${ }^{3}$ Although there is variability with con- 
sumption throughout the country, with Balochistan having the highest prevalence of users, all regions were involved. Punjab, due to its large share of the population, has the highest number of opioid abusers with 2.9 million. Moreover, approximately $80 \%$ of users in Punjab who inject opioids admit to sharing syringes regularly.

Fortunately, there is much Pakistan can learn from America's challenges with opioid abuse. These lessons include: avoiding the trap of aggressively treating pain under the guise of good patient care, active education of physicians and medical students on the risks of opioid addiction and learning best opioid prescribing habits, curbing the influence on the pharmaceutical industry on opioid consumption, and keeping pressure on public officials to fight illegal opioid entrance into the country. Ultimately, it will be the medical commu- nity, and in particular leaders like those at the King Edward Medical University, that will have to both face this problem and ultimately address it heads on.

\section{References}

1. The Opioid Epidemic: By the Numbers. US Health \& Human Services 2016.

2. Kim N, Matzon JL, Abboudi J, Jones, C, Kirkpatrick W, Leinberry CF. Liss FE, Lutsky KF, Ilyas AM. A Prospective Evaluation of Opioid Utilization after Upper Extremity Surgical Procedures: Identifying Consumption Patterns and Determining Practice Guidelines. J Bone Joint Surg Am. 2016; 98 (20): e89.

3. Drug use in Pakistan 2013 report - UN Office on Drugs and Crime, 2013.
Asif M. Ilyas MD, FACS

Program Director of Hand Surgery Associate Professor of Orthopaedic Surgery

Thomas Jefferson University Philadelphia, Pennsylvania, USA 